\title{
ARMS-PCR for detection of BRAF V600E hotspot mutation in comparison with Real-Time PCR-based techniques
}

\author{
Marcin M. Machnicki1”, Eliza Glodkowska-Mrowka1\#, Tomasz Lewandowski², Rafał Ploski³, \\ Pawel Wlodarski ${ }^{4}$ and Tomasz Stoklosa ${ }^{\boxplus}$ \\ 'Department of Immunology, Medical University of Warsaw, Warsaw, Poland; 2Department of Chemotherapy, The Maria Sklodowska-Curie Me- \\ morial Cancer Center and Institute of Oncology, Warsaw, Poland; ${ }^{3}$ Department of Medical Genetics, and ${ }^{4}$ Department of Histology and Embry- \\ ology, Center for Biostructure Research, Medical University of Warsaw, Warsaw, Poland
}

\begin{abstract}
BRAF mutation testing is one of the best examples how modern genetic testing may help to effectively use targeted therapies in cancer patients. Since many different genetic techniques are employed to assess BRAF mutation status with no available comparison of their sensitivity and usefulness for different types of samples, we decided to evaluate our own PCR-based assay employing the amplification refractory mutation system (ARMS-PCR) to detect the most common hotspot mutation c. T1799A (p. V600E) by comparing it with two qPCR based assays: a commercially available test with hybridizing probes (TIB MOLBIOL) and high resolution melting (HRM). Positive results were verified with Sanger sequencing. DNA from two cancer cell lines with known mutation status and from tissue samples from melanoma and gastric cancer was used. ARMS-PCR was the most sensitive method with the level of detection of the mutant allele at $2 \%$. Similar sensitivity was observed for the qPCRbased commercial test employing hybridizing probes; however, this test cannot exclude negative results from poor or low quality samples. Another qPCR-based method, HRM, had lower sensitivity with the detection level of approximately $20 \%$. An additional drawback of HRM methodology was the inability to distinguish between wild type and mutant homozygotes in a straightforward assay, probably due to the character of this particular mutation $(T>A)$. Sanger sequencing had the sensitivity of the detection of mutant allele similar to HRM, approx. $20 \%$. In conclusion, simple ARMS-PCR may be considered the method of choice for rapid, cost-effective screening for BRAF p. V600E mutation.
\end{abstract}

Key words: BRAF mutation screening, molecular diagnostics

Received: 16 August, 2012; revised: 15 December, 2012; accepted: 14 January, 2013; available on-line: 05 February, 2013

\section{INTRODUCTION}

In recent years, the $B R A F$ gene encoding a cytoplasmic serine/threonine kinase, has become a highlight of targeted treatment concept in cancer therapy. Initial discovery of $B R A F$ mutations in a variety of cancers (Davies et al., 2002), followed by research on the role of $B R A F$ in carcinogenesis have led to the successful introduction of its inhibitor, vemurafenib (formerly PLX4032) (Chapman et al., 2011), marking a significant progress in the treatment of advanced melanoma, and opening new therapeutic possibilities in other cancers (Kopetz S, 2010).

BRAF kinase is one of the major components of the RAS-RAF-MEK-ERK mitogen-activated protein kinase signalling pathway, which has a crucial impact on cell proliferation (Robinson \& Cobb, 1997), therefore the discovery of $B R A F$ activating mutations quickly led to its recognition as an oncogene (Garnett \& Marais, 2004). In contrast to wild-type BRAF, physiologically activated by RAS protein, constitutively active BRAF mutants phosphorylate their downstream targets in a RAS-independent manner, which results in mitogen-independent signalling (Wan et al., 2004). While it is currently accepted that oncogenic $B R A F$ is incapable of driving tumorigenesis alone (Michaloglou et al., 2005) and mutations are frequently observed in benign skin lesions (Pollock et al., 2003), tumors harbouring $B R A F$ mutation are highly dependent on its effects (Hingorani et al., 2003; Solit et al., 2006). This is reflected in the significant prevalence of $B R A F$ variants in many types of cancer. Mutations can be found at high frequencies in melanoma $(40 \%-68 \%$ of samples) (Kumar et al., 2003; Davison et al., 2005), papillary thyroid carcinoma (36-69\%) (Cohen et al., 2003; Trovisco et al., 2004), nervous system tumors (up to 66\%) (Schindler et al., 2011) and they are present virtually in every case of hairy-cell leukemia (Tiacci et al., 2011; Arcaini et al., 2012). Furthermore, $B R A F$ mutations are detected at lower frequencies in other cancers, such as multiple myeloma (4\%) (Chapman et al., 2011), colorectal (7.2-22\% of samples) (Wang et al., 2003; Saridaki et al., 2011) and adrenocortical carcinomas (5.7\%) (Kotoula et al., 2009) as well as lung adenocarcinomas (1.6-2\%) (Naoki et al., 2002; Schmid et al., 2009). Apart from those cancers, $B R A F$ seems to be implicated in development of Langerhans' cell histiocytosis, where its mutations are present in $57 \%$ of cases (Badalian-Very et al., 2010), and cardiofaciocutaneous syndrome, where $78 \%$ of individuals have germline $B R A F$ mutations (Rodriguez-Viciana et al., 2006).

The characteristic feature of $B R A F$ variants is their restricted diversity. Generally, exons 11 and 15 are most frequently being affected by various substitutions (Davies et al., 2002), but an overwhelming majority of mutations can be found in codon 600 in exon 15 and one of them, the c. T1799A substitution resulting in valine to glutamic

$\triangle$ e-mail: tomasz.stoklosa@wum.edu.pl

\#These authors contributed equally to this work

Abbreviations: HRM, high resolution melting; ARMS, amplification refractory mutation system; qPCR, Real-Time quantitive PCR; PCR, polymerase chain reaction 
acid change (p. V600E), accounts for $80-100 \%$ of mutations (Kumar et al., 2003; Houben et al., 2004; Libra et al., 2005; Tiacci et al., 2011).

Ubiquity of $B R A F$ mutations, along with their uniformity and availability of BRAF inhibitors implies a promising perspective for targeted therapy. However, $B R A F$ mutation status can also serve as a predictive or prognostic factor, as in colorectal cancer. Clinical response of the anti-EGFR treatment in colorectal cancer with anti-EGFR antibodies (e.g. cetuximab, panitumumab) depends on preserved wild-type status of $B R A F$ (as well as KRAS) (Di Nicolantonio et al., 2008). In this tumor, $B R A F$ alterations were also found to correlate with worse survival, making $B R A F$ mutation status a strong prognostic factor (Di Nicolantonio et al., 2008; Yokota et al., 2011).

Therefore, there is a growing need to screen for the status of BRAF mutation in different tumors and although there are several different methods available there are only few reports comparing some of the methods (Yancovitz et al., 2007; Ellison et al., 2010). Moreover, there is a need for a cheap and sensitive PCR-based assay to rapidly and reliably check the status of BRAF.

Here we decided to detect hotspot c. T1799A (p. V600E) mutation employing three different PCRbased screening methods, i.e. Amplification Refractory Mutation System PCR (ARMS) (Newton et al., 1989), High Resolution Melting (HRM) (Wittwer et al., 2003) and commercially available, BRAF T1799A (p. V600E) mutation-targeted qPCR with hybridizing probes. Since Sanger sequencing is commonly used to verify results obtained with different methods, we also applied this technique to confirm the results of PCR-based methods and to compare their sensitivity and specificity.

\section{MATERIALS AND METHODS}

Cell lines and patient samples. Optimization and comparison of different detection methods were performed using two human cancer cell lines: A375 melanoma cell line harbouring homozygous BRAF c. T1799A (p. V600E) mutation, and MIA PaCa-2 pancreatic cancer cell line homozygous for the wild-type $B R A F$ allele and harbouring mutually exclusive homozygous $K R A S \mathrm{c}$. G34T (p. G12C) mutation (COSMIC Database, Forbes et al., 2011) as well as gastric cancer samples, which were obtained from fresh tumor tissue, collected intraopera- tively or gastroscopically with patients' informed consent and approval from relevant Ethics Committee. Additionally, reference melanoma DNA samples with known mutation status were kindly provided by Dr. Ahmad Jalili (Division of Immunology, Medical University of Vienna). Two of them (MM1 and MM2) had wild-type genotypes and two (MM3 and MM4) were heterozygous for BRAF c. T1799A mutation.

Cell lines were cultured in Dulbecco's Modified Eagle's Medium (D6429, Sigma-Aldrich), supplemented with antibiotic-antimycotic solution (A5955, Sigma-Aldrich) and $10 \%$ fetal bovine serum at $37^{\circ} \mathrm{C}$ in an atmosphere enriched with $5 \% \mathrm{CO}_{2}$ at $95 \%$ relative humidity.

For comparison of the sensitivity of detection methods DNA from A375 and MIA PaCa- 2 cell lines were mixed to create samples containing $50 \%, 20 \%$ and $2 \%$ of the A375 DNA. Furthermore, various DNA samples were diluted 10-, 100- and 1000-fold for the same purpose.

All samples are listed in Table 1.

DNA extraction from cancer samples and cell lines was performed using proteinase $\mathrm{K}$ and JETFLEX Genomic DNA Purification Kit (GENOMED). After extraction DNA was dissolved in water and quantified spectrophotometrically with NanoDrop 2000 (Thermo Scientific). Typically, DNA concentration varied between 100-500 ng/ $\mu \mathrm{l}$.

\section{ARMS}

The ARMS assay (Newton et al., 1989), a simple PCRbased technique, utilizes a phenomenon of amplification arrest caused by non-complementary nucleotide(s) at $3^{\prime}$ end of the primer. In this study we used a mutation-specific primer, resulting in formation of an additional product only in the presence of the c. A1799 allele. Three primers were used in a total concentration of $400 \mathrm{nM}$ : one forward primer 5'-GCT'TGCTCTGATAGGAAAATGAG-3' and two reverse primers 5'-ACCCACTCCATCGAGAT'T'TCT-3' (mutation specific) and 5'-CTGTGGATCACACCTGCCT'TA-3' (control) at the concentrations of $133 \mathrm{nM}, 173 \mathrm{nM}$ and 93 $\mathrm{nM}$, respectively. The $25 \mu \mathrm{l}$ reaction mixture consisted of $1.25 \mathrm{U}$ HotStartTaq polymerase (Qiagen), $160 \mu \mathrm{M}$ dNTPs (VWR), $1 \times$ Coral Load PCR Buffer (Qiagen), $1.5 \mathrm{mM} \mathrm{MgCl}$ and from $100 \mathrm{ng}$ to $500 \mathrm{ng}$ of genomic DNA (the latter concentration for clinical samples). PCR

Table 1. Samples used for BRAF c. T1799A (p. V600E) mutation detection method comparison.

\begin{tabular}{|c|c|c|c|c|c|c|c|}
\hline \multirow{2}{*}{ Sample type } & \multirow{2}{*}{ Sample name } & \multirow{2}{*}{$\begin{array}{l}\text { Number of sam- } \\
\text { ples studied }\end{array}$} & \multirow{2}{*}{ BRAF c.T1799A mutation status } & \multicolumn{4}{|c|}{ Mutation status by } \\
\hline & & & & ARMS & SEQ & $\mathrm{HP}$ & HRM \\
\hline $\begin{array}{l}\text { Malignant melanoma cell } \\
\text { line }\end{array}$ & A375 & NA & $+/+$ & + & $+/+$ & + & $-^{*}$ \\
\hline Pancreatic cancer cell line & MIA PaCa-2 & NA & $-1-$ & - & $-1-$ & - & $-{ }^{*}$ \\
\hline \multirow{3}{*}{$\begin{array}{l}\text { A375 and MIA PaCa-2 cell } \\
\text { line mix }\end{array}$} & \multirow{3}{*}{$\begin{array}{l}\text { of } \mathrm{A} 375 \\
\text { content }\end{array}$} & NA & $\operatorname{mix} 50: 50$ & + & $+/-$ & nt & $+^{*}$ \\
\hline & & NA & $\operatorname{mix} 80: 20$ & + & $+1-$ & nt & $+*$ \\
\hline & & NA & $\operatorname{mix} 98: 2$ & + & $-1-$ & nt & $-{ }^{*}$ \\
\hline \multirow{2}{*}{ Malignant melanoma } & MM1-2 & 2 & $-1-$ & - & $-1-$ & nt & $-{ }^{*}$ \\
\hline & MM3-4 & 2 & $+/-$ & + & $+/-$ & nt & $+^{*}$ \\
\hline \multirow{2}{*}{ Gastric cancer } & GC4 & 1 & $+1-$ & + & $-1-$ & + & $-^{*}$ \\
\hline & $\mathrm{GC} 1-3,5-69$ & 68 & $-/-$ & - & $-/-$ & - & $-^{*}$ \\
\hline
\end{tabular}

Abbreviations and markings: NA, not applicable; SEQ, sequencing; HP, hybridizing probes; +/+, homozygous mutated; +/-, heterozygous; -/- homozygous wild-type; mix, mixed DNA from MIA PaCa-2 and A375 cell lines; +, mutated; - , wild-type; nt, not tested; +*, or $-{ }^{*}$, sample clustered to heterozygote or homozygote group, respectively. 
was carried out for 40 cycles $\left(40 \mathrm{~s}\right.$ at $94^{\circ} \mathrm{C}, 40 \mathrm{~s}$ at $61^{\circ} \mathrm{C}$, $40 \mathrm{~s}$ at $72^{\circ} \mathrm{C}$ ), with initial denaturation for $15 \mathrm{~min}$ at $95^{\circ} \mathrm{C}$ and final extension for $5 \mathrm{~min}$ at $72^{\circ} \mathrm{C}$, using Mastercycler Epigradient (Eppendorf), resulting in formation of one or two amplicons: $623 \mathrm{bp}$ (control) and $134 \mathrm{bp}$ (mutation). Results for all DNA samples were obtained in at least two independent experiments.

DNA Electrophoresis. All PCR products were separated on $1-2 \%$ agarose gels (Sigma-Aldrich) stained with ethidium bromide (Fluka Analytical, Sigma Aldrich). Gel images were acquired with Alphaimager Mini (Protein Simple).

DNA Sequencing. DNA sequences were obtained in two PCR reactions, followed by sequencing in both directions on ABI 3730 automatic sequencer with capillary electrophoresis (Applied Biosystems). Two primers (Di Nicolantonio et al., 2008), forward 5'-TGCT'TGCTCTGATAGGAAAATG-3' and reverse 5'-AGCATCTCAGGGCCAAAAAT-3', were used for both amplifications.

Preparative PCR was carried out for 35 cycles $(40 \mathrm{~s}$ at $94^{\circ} \mathrm{C}, 40 \mathrm{~s}$ at $58^{\circ} \mathrm{C}, 40 \mathrm{~s}$ at $72^{\circ} \mathrm{C}$ ), with initial denaturation for $15 \mathrm{~min}$ at $95^{\circ} \mathrm{C}$ and final extension for $5 \mathrm{~min}$ at $72^{\circ} \mathrm{C}$, resulting in formation of $228 \mathrm{bp}$ product, using a $25 \mu \mathrm{l}$ mixture of $1.25 \mathrm{U}$ HotStartTaq polymerase, $2 \times$ $200 \mathrm{nM}$ primers, $160 \mu \mathrm{M}$ dNTPs, $1 \times$ PCR Buffer (Qiagen), $1.5 \mathrm{mM} \mathrm{MgCl}_{2}$ and $100-500 \mathrm{ng}$ of genomic DNA.

Subsequently, $10 \mu \mathrm{l}$ of product was purified with Shrimp Alkaline Phosphatase (1U) and Exonuclease I $(10 \mathrm{U})$ (Fermentas) and reamplified with BigDye Terminator v3.1 Cycle Sequencing kit (Applied Biosystems) for 55 cycles $\left(10 \mathrm{~s}\right.$ at $95^{\circ} \mathrm{C}, 15 \mathrm{~s}$ at $50^{\circ} \mathrm{C}, 90 \mathrm{~s}$ at $\left.60^{\circ} \mathrm{C}\right)$ with initial denaturation for $5 \mathrm{~min}$ at $95^{\circ} \mathrm{C}$ and final extension for $5 \mathrm{~min}$ at $60^{\circ} \mathrm{C}$ in a $10 \mu \mathrm{l}$ mixture of $0.4 \mu \mathrm{l}$ BigDye 3.1, 3.6 $\mu \mathrm{l}$ Sequencing Buffer, $0.002 \mathrm{nM}$ primer (forward or reverse) and $2 \mu \mathrm{l}$ product from the previous step.

Finally, products were purified on Centri-Sep CS-901 Columns with Sephadex (Princeton Separations) and processed for sequencing. All DNA sequences were obtained in at least two independent experiments.
Real-time PCR-based methods. Two detection methods, namely qPCR with hybridizing probes and High Resolution Melting (HRM) were carried out in LightCycler ${ }^{\text {TM }} 480$ instrument (Roche). All samples were amplified in a volume of $20 \mu \mathrm{l}$ in duplicates in 96-well plates. Acquired data was analysed with LightCycler 480 Software (release 1.5.0.39 SP4). Real-time PCR with fluorescent hybridizing probes was performed with application of LightMix ${ }^{\text {TM }}$ Kit BRAF V600E (TIB MOLBIOL), according to the manufacturers manual. Reaction components and cycling and melting parameters are provided in supplementary Table 1 and 2 (at www.actabp. $\mathrm{pl}$ ). Sample mutation status was determined using the melting temperature analysis (Tm calling mode). For the HRM analysis LightCycler ${ }^{\text {TM }} 480$ High Resolution Melting Master Real-Time (Roche) was used in accordance with the manufacturer's manual. This method allows to detect point mutations by measuring the change of amplicon melting behaviour versus controls of known genotype. Since amplicon length has a crucial impact on the melting process, three different pairs of primers flanking the V600 codon were designed: forward 5'-T'TCATGAAGACCTCACAGTAAAAA-3' and reverse 5'-CTGATGGGACCCACTCCAT-3' for $77 \mathrm{bp}$ amplicon, forward 5'-TCACAGTAAAAATAGGTGAT'T'TTGG-3' and reverse 5'-CCACAAAATGGATCCAGACA-3' for 95 bp amplicon, forward 5'-GCACAGGGCATGGATTACT'T-3' and reverse 5'-GATGACT'TCTGGTGCCATCC-3' for 195 bp amplicon. Reaction components as well as cycling and melting parameters are provided in supplementary Table 3 and 4 (at www.actabp.pl). Initial experiments allowed to establish the optimal $\mathrm{MgCl}_{2}$ and DNA concentrations at $3 \mathrm{mM}$ and $30 \mathrm{ng} /$ reaction, respectively. Sample mutation status was determined using Gene scanning mode, with fluorescence level and temperature normalizations (normalization and temperature shift options) applied when necessary. Samples were clustered automatically and visual analysis was applied only to corroborate the results.
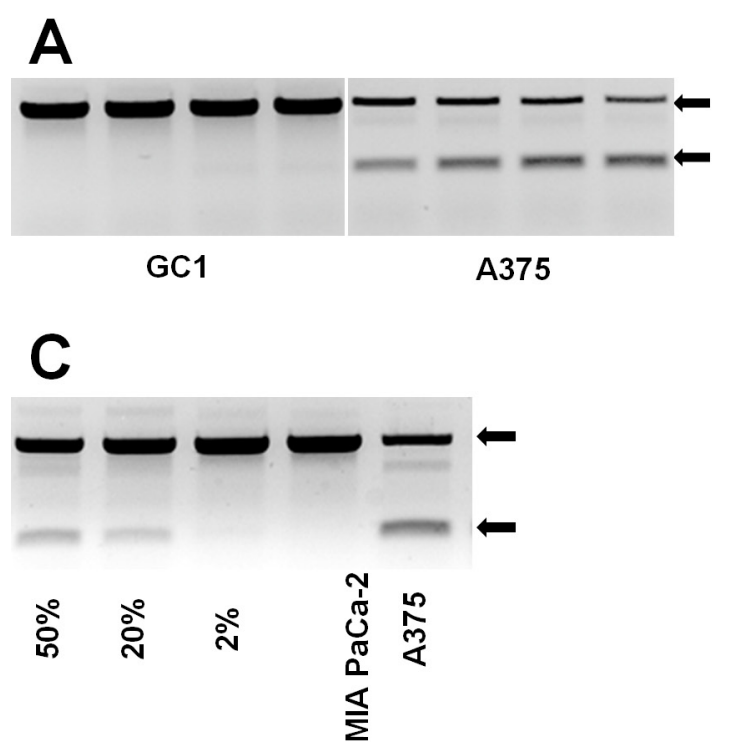

B

\begin{tabular}{l|c|c}
\hline Primer & \multicolumn{2}{|c}{ Proportion } \\
\hline Forward & 1 & 1 \\
\hline Reverse & 1 & 0.7 \\
\hline Mutation specific & 1 & 1.3 \\
\hline Total concentration & $600 \mathrm{nM}$ & $400 \mathrm{nM}$ \\
\hline
\end{tabular}

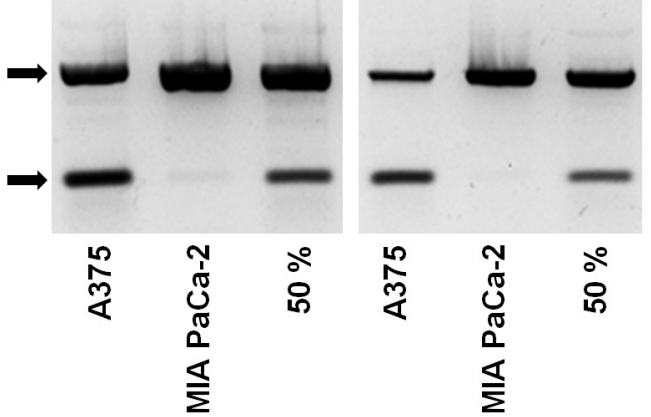

Figure 1. Optimization of the ARMS assay for BRAF c. T1799A (p. V600E) detection.

(A) Comparison of product specificity at various annealing temperatures. Four temperatures were tested $\left(63.6^{\circ} \mathrm{C}, 61.4^{\circ} \mathrm{C}, 58.0^{\circ} \mathrm{C}\right.$ and $56.2^{\circ} \mathrm{C}$, from left to right). $61^{\circ} \mathrm{C}$ was chosen as resulting in best specificity without loss of amplification efficiency. The GC1 sample harbours a wild type BRAF allele and mutually exclusive KRAS mutation. (B) Increase in ARMS products' specificity (left to right) after changing proportions of the primers and their total concentration. (C) Detection sensitivity of c. A1799 allele after 35 cycles of amplification (no detection at $2 \%$ content). Arrows indicate positions of the expected products: control (upper $-623 \mathrm{bp}$ ) and mutation specific (lower $-134 \mathrm{bp})$. 


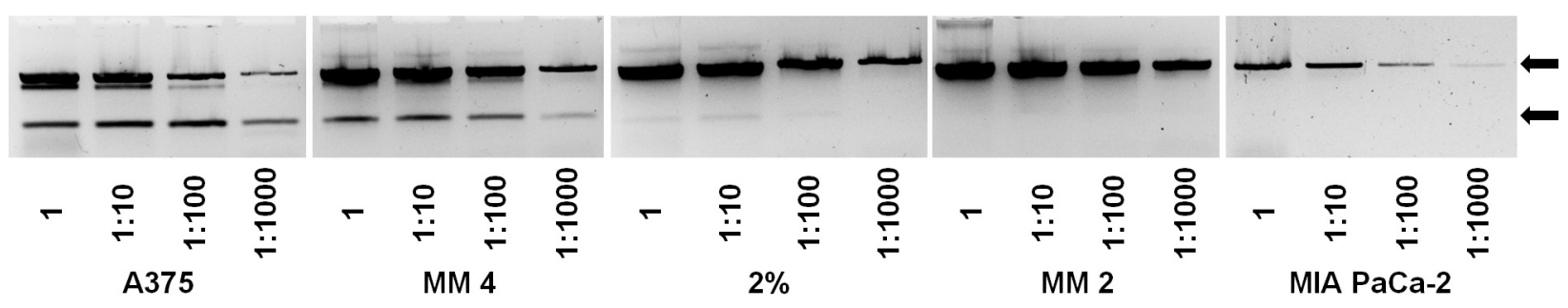

Figure 2. Sensitivity of BRAF c. T1799A (p. V600E) detection with optimized ARMS assay.

ARMS detects C. A1799 allele in homozygous A375 cell line and heterozygous melanoma sample even at 1000-fold dilution. Conversely, it does not generate false positive results from homozygous wild-type melanoma and MIA PaCa- 2 cell line samples (only control bands are visible). Simultaneously, ARMS discriminates samples containing at least 2\% C. A1799 allele from wild-type samples.

Bioinformatic tools. Genomic sequence of $B R A F$ was derived from NCBI database, accession number NG_007873.1. Primers were designed using primer3 (Rozen \& Skaletsky, 2000), primerBLAST (http://www. ncbi.nlm.nih.gov/tools/primer-blast/) and NetPrimer (http://www.premierbiosoft.com/netprimer/index. html). Collected DNA sequences were analysed with FinchTV 1.4.0 software (Geospiza, Inc.; Seattle, WA, USA; http:/ /www.geospiza.com) and aligned in Jalview 2.6.1 (Clamp et al., 2004; Waterhouse et al., 2009) with MAFFT6 algorithm (Katoh et al., 2002; Katoh \& Toh, 2008). Sequences were processed with JustBio online tools (http://www.justbio.com) when needed.

\section{RESULTS}

\section{ARMS}

Initial experiments were designed to establish optimal conditions for ARMS. To ensure the formation of specific products, annealing temperature was set as high as possible, i.e. $61^{\circ} \mathrm{C}$ (Fig. 1A), and total concentration of primers was lowered from initial $600 \mathrm{nM}$ to $400 \mathrm{nM}$, in proportions of 1:0.7:1.3 (forward:reverse:mutation specific, respectively; initially 1:1:1) (Fig. 1B), while the number of cycles was increased from initial 35 to 40, allowing for better sensitivity (Fig. 1C).

After optimization of the ARMS assay we performed sensitivity tests using DNA isolated from cell lines and clinical melanoma samples with various c. A1799 allele content at 1-1000-fold dilutions. ARMS allowed us to detect the c. T1799A mutation in heterogeneous melanoma samples even at 1000 -fold dilution, whereas minimal detectable c. A1799 allele content was at least 2\%. Si-
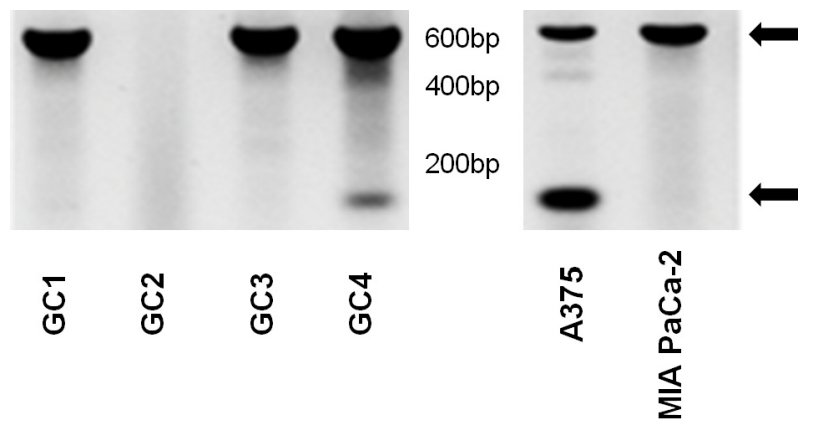

Figure 3. Evaluation of ARMS on gastric cancer samples.

ARMS assay allows to detect c. T1799A ( $p$. V600E) mutation in GC4 positive gastric cancer sample. In GC2 no band is visible, suggesting low quality of the used DNA (upper band serves as an internal control of amplification). Arrows indicate positions of the expected products: control (upper -623 bp), mutation (lower - 134 bp). multaneously, the results obtained from negative control samples excluded the possibility of false positive results (Fig. 2). To evaluate ARMS usefulness as a diagnostic tool we performed mutation screening in a small group of gastric cancer samples, resulting in detection of the c. T1799A mutation in one of them (Fig. 3). Arrows indicate positions of the expected products: control (upper - $623 \mathrm{bp}$ ), mutation (lower — $134 \mathrm{bp}$ ). Dilutions are specified below the gel images. Highest dilutions (1:1000) resulted in $0.1-0.5 \mathrm{ng}$ of DNA per reaction.

\section{DNA Sequencing}

To determine the reliability of ARMS we sequenced DNA from both control cell lines and two gastric cancer samples, positive and negative for BRAF c. T1799A mutation, in both directions. In three cases sequencing data were consistent with ARMS results, while chromatogram of GC4 sample displayed a peak for the wild-type nucleotide only (Fig. 4A).

We investigated this discrepancy by sequencing samples containing $50 \%, 20 \%$ and $2 \%$ of A375 DNA. The mutation was not detectable at the $2 \%$ level, thus showing lower sensitivity of sequencing compared to ARMS (Fig. 4B).

Hybridizing probes. Application of hybridizing probes allowed for accurate $B R A F$ c. T1799A mutation detection; we observed no false positive results among

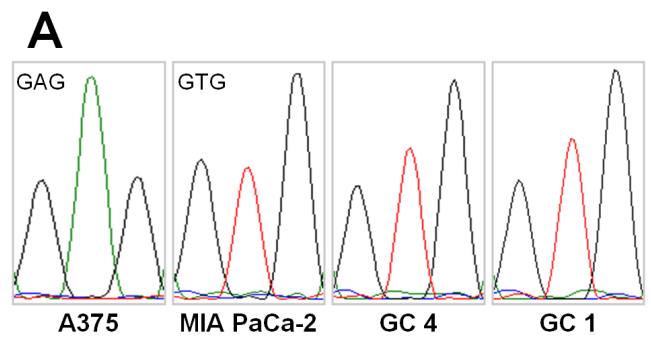

B

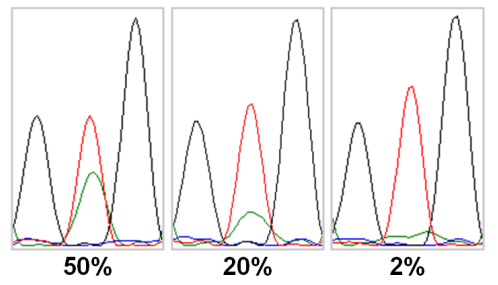

Figure 4. Chromatograms from sequence analysis of BRAF p. 600 codon (c. 1798-1800).

(A) C. T1799A mutation in GC4 sample is not detectable with sequencing - an adenine peak cannot be observed. (B) Sensitivity test of sequencing at various C. A1799 allele contents shows no C. T1799A mutation detection at $2 \%$ level, and a small adenine peak at $20 \%$ level. 


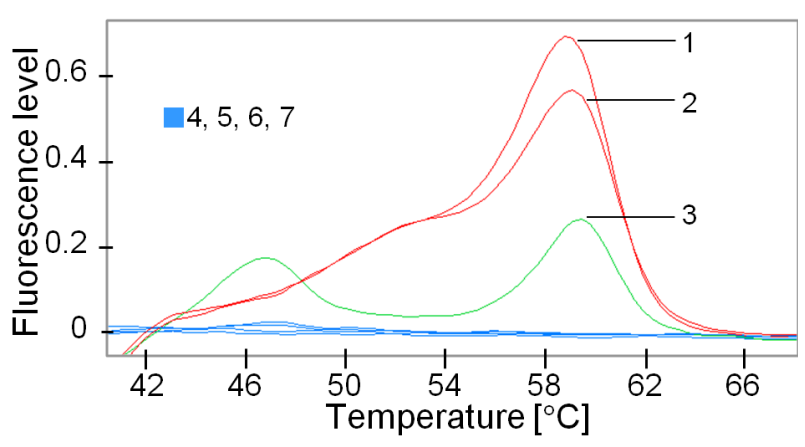

Figure 5. Exemplary melting curves obtained with LightMix Kit BRAF V600E hybridizing probes.

C. T1799A mutation is detected in GC4 sample (3), thus suggesting detection sensitivity comparable to that of the ARMS assay. Samples negative for c. T1799A mutation (4-6) are clustered together with no template control (7). Sample description: 1, A375; 2, positive control DNA provided by manufacturer; $3, \mathrm{GC4}, 4, \mathrm{GC} 3$; 5 , GC5; 6, GC6; 7, no template control.

the tested samples. The sensitivity of this method was similar to that of ARMS assay since it allowed for $\mathrm{c}$. T1799A mutation detection in the GC4 sample, albeit its detection mechanism does not exclude the possibility of interpretation of low DNA quality samples as negative

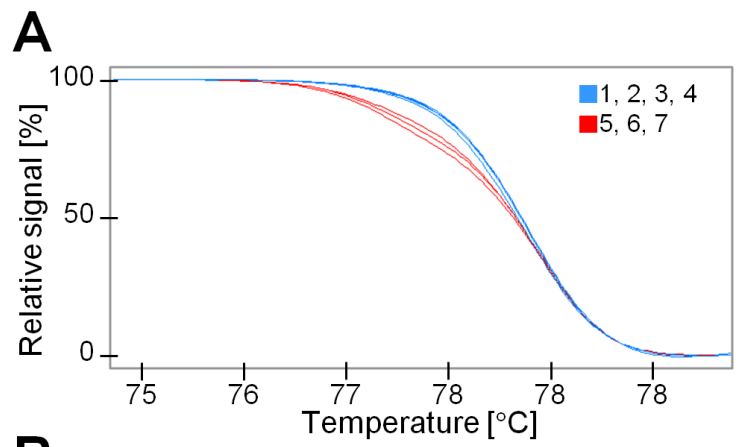

B

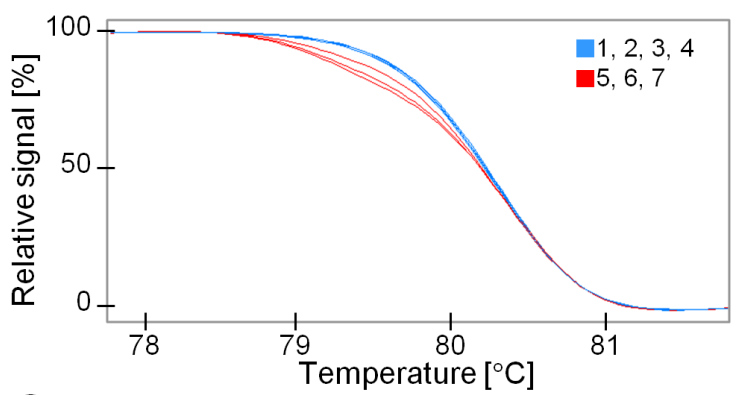

$\mathrm{C}$

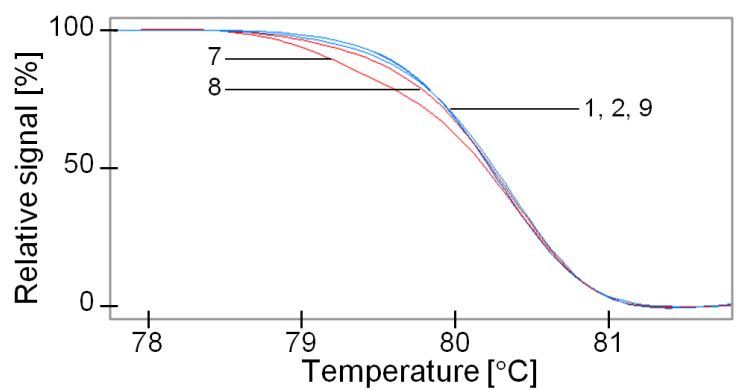

Table 2. Comparison of sensitivity and specificity of ARMS and hybridizing probes.

*LightMix BRAF V600E kit does not allow to discriminate wild type and no template or low quality template results (as verified with the manufacturer).

\begin{tabular}{lcc}
\hline Sample type & ARMS & hybridizing probes \\
\hline Number of: & 1 & 1 \\
\hline positive & 68 & $68^{*}$ \\
\hline negative & 0 & 0 \\
false positive & 0 & $0^{*}$ \\
\hline false negative & & \\
\hline
\end{tabular}

(there is no internal amplification control according to the manufacturer's information (Fig. 5).

High Resolution Melting. Finally, we made an attempt to optimize and use the HRM method for c. T1799A mutation detection. We designed three pairs of primers flanking the p. 600 codon, amplifying products of different sizes. We could not obtain coherent and reproducible results for the $195 \mathrm{bp}$ amplicon, thus the corresponding primer pair was excluded from further tests. The other two primer pairs allowed only to discriminate between homo- and heterozygous samples,
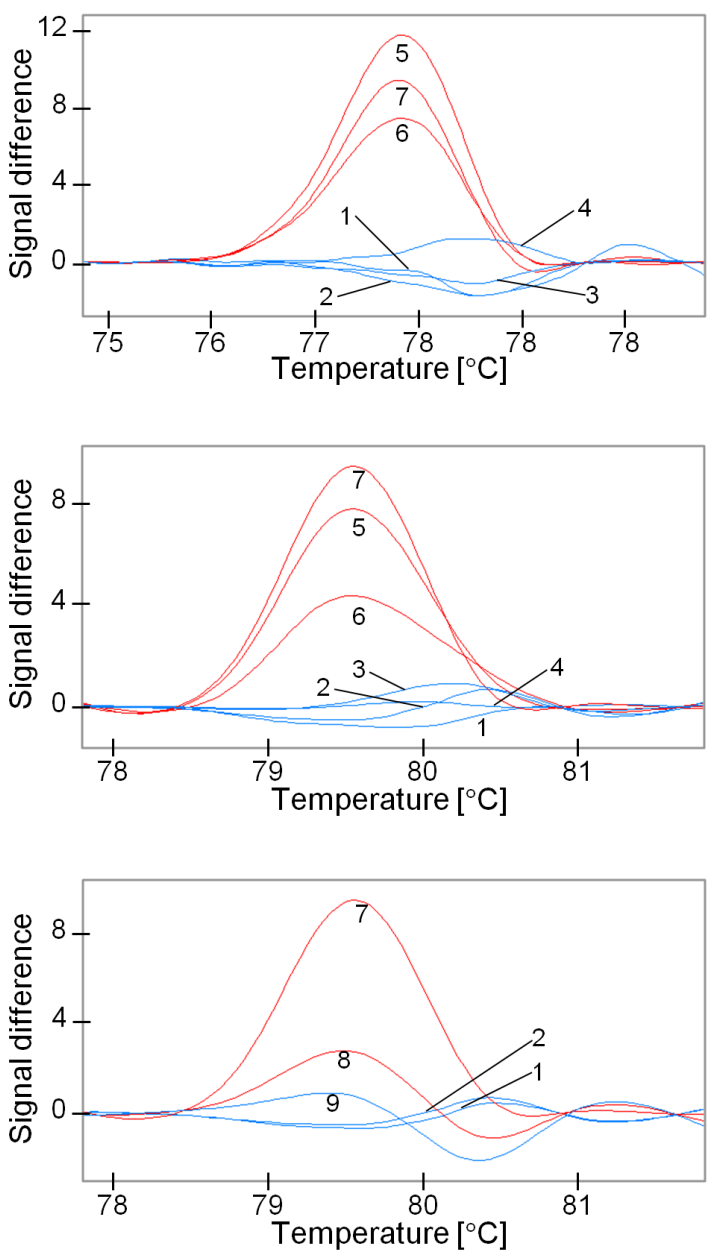

Figure 6. Melting curves and corresponding difference plots of the 77 and $95 \mathrm{bp}$ amplicons generated during HRM.

(A) and (B) HRM allows only to discriminate homo- and heterozygote, regardless of amplicon length (A, 77 bp; B, 95 bp). Wild-type MM samples are in the homozygotes group (blue curves), while heterozygous MM and $50 \%$ samples create a separate group (red curves). Melting curves were normalized and temperature-shifted. (C) Sensitivity test of HRM using the $95 \mathrm{bp}$ amplicon. Samples must contain at least $20 \%$ of c. A1799 allele to be classified as heterozygotes (red curves) and therefore as mutated. Melting curves were normalized and temperature-shifted. Sample description: 1, A375; 2, MIA PaCa-2; 3, MM1; 4, MM2; 5, MM3; 6, MM4; 7, 50\%; 8, 20\%; 9, 2\%. 
since homozygous samples were clustered together, regardless of their mutation status (Fig. 6A and 6B).

The GC4 sample was classified to the homozygous sample group, despite the mutation detected by ARMS (Fig. 3) and hybridizing probes (Fig. 5), therefore we decided to test the sensitivity of HRM with samples containing $50 \%, 20 \%$ and $2 \%$ of c. A1799 allele using the $95 \mathrm{bp}$ amplicon primer pair. As expected, the 2\% sample was clustered together with homozygotes, suggesting that HRM sensitivity was similar to that of sequencing (Fig. 6C).

To conclude, HRM allowed only for discrimination of homo- and heterozygous samples, containing at least $20 \%$ of the c. A1799 allele. Upper c. A1799 allele content limit was not determined. A summary of the results is shown in Table 1.

\section{Sensitivity and specificity of mutation detection using ARMS and hybridizing probes}

As the results of HRM analysis of BRAF c. T1799A mutation were unsatisfactory we decided to compare sensitivity and specificity of ARMS and hybridizing probes only and corroborate their results with Sanger sequencing. To achieve that goal we decided to scan 69 clinical samples obtained during gastric cancer resection with the above methods. Both ARMS and hybridizing probes allowed for detection of BRAF c. T1799A mutation in a single sample (GC4), (Table 2). We observed no false positive or false negative results.

\section{DISCUSSION}

Determining $B R A F$ mutation status is becoming a routine genetic procedure in cancer diagnostics. However, there is no widely accepted gold standard assay for $B R A F$ mutation detection. The aim of our study was to compare different methods, including ARMS-PCR designed by us, for the detection of the BRAF c. T1799A mutation, which is the most common among $B R A F$ tumour associated variants. Apart from the functional consequences, this phenomenon allows for application of various detection methods, with different sensitivity, costs, labour intensity or instrument requirements.

Our ARMS assay proved to be very sensitive, detecting the c. A1799 allele even at less than 2\%. This is not surprising, as various amplification-based methods were shown to be highly sensitive in previous studies. Pyrophosphorolysis-activated polymerization, ARMS with fluorochrome labelling and nested allele-specific PCR allowed to detect the $B R A F$ mutation even below the $1 \%$ level, although at the cost of more sophisticated reaction mechanisms (Yancovitz et al., 2007; Janssen et al., 2008; Maat et al., 2008; Ellison et al., 2010). This is in contrast with the low sensitivity of Sanger sequencing demonstrated here or in previous studies (Yancovitz et al., 2007), which requires from $20 \%$ to $30 \%$ of the mutant allele for its detection. Application of more sensitive methods allowed to discover $B R A F$ mutations in uveal melanomas, initially described as negative (Janssen et al., 2008; Maat et al., 2008), which raises a question whether some data assessing $B R A F$ mutation frequency, obtained with sequencing, could have been underestimated.

While the c. T1799A (p. V600E) is a predominant $B R A F$ polymorphism, rare tandem codon 600 mutations were found to have similar functional consequences (Garnett \& Marais, 2004; Wan et al., 2004). Our ARMS assay is presumably incapable of detecting most of them, including the p. V600E arising from c. TG1799-1800AA.
However, it can be used to detect the c. GT17981799AA/p. V600K tandem mutation. Rubinstein et al. (2010) suggested that p. V600K prevalence in melanoma was underestimated, reaching approximately $16.3 \%$ of all codon 600 mutations, and demonstrated clinical response to vemurafenib in a patient with an advanced, $\mathrm{p}$. V600K-positive tumor.

One of the essential advantages of our ARMS assay is its simplicity. The qPCR-based ARMS method described by Ellison et al. (2010) displayed a similar sensitivity of $1 \%$ and possessed the ability to detect three different mutations (p. V600E, p. V600K and p. V600D). However, this methodology requires the use of a real-time thermocycler and six different oligonucleotides, including two pairs of primers and two fluorescent probes containing locked nucleic acid nucleotides, thereby considerably increasing the complexity of the reaction. It must be noted, however, that it also eliminates the need for gel electrophoresis, excludes the possibility of accidental contamination after the amplification and facilitates the assay's preparation, but at a considerably higher cost.

Additionally, ARMS versatility was proven by applying it to detect other gene mutations e.g. JAK2 c. G1849T (Chen et al., 2007) or NOTCH1 c. 7544-7545delCT (Rossi et al., 2012). Real-time PCR-based ARMS technique has also been successfully implemented to detect $N-R A S$ c.A182G or c.C181A mutations in melanoma (Ellison et al., 2010).

We tried to utilize real-time PCR-based methods as an alternative for our ARMS assay. The first one, the LightMix hybridizing probe kit allowed us to confirm ARMS results, thus showing similar sensitivity, though the usefulness of the assay is doubtful because of the lack of an internal amplification control.

The overall performance of the second one, HRM assay was unsatisfactory in our experimental settings. Low sensitivity, combined with the inability to distinguish between homo- and heterozygous or mixed samples, in our opinion disqualifies this method from the $B R A F$ mutation status testing. This was quite unexpected, as we have successfully employed HRM for point mutations in other genes (unpublished data), using the same instrument and reagents. A possible explanation is that the $\mathrm{T}>\mathrm{A}$ transversion alters the homozygous amplicon's melting temperature insufficiently and only when heteroduplexes are formed, a significant change in melting behaviour can be observed. Herrmann et al. (2007) obtained similar results for $H B B$ c. A20T mutation and demonstrated that discrimination can also be hampered by temperature variation across the plate, which limits the effective resolution of heat block instruments, including LC480 (Herrmann et al., 2007). Although there is a possibility to detect homozygous variants by mixing wild-type and unknown DNA with HRM, so that any homozygous variant in the unknown sample will be detected as a heterozygote in the mixture, we decided not to utilize this method as it is more labor-intensive and may affect reproducibility of the results.

It is tempting to speculate on the rational level of desired detection sensitivity. If we consider testing pure, homo- or heterozygous samples, then every method tested here has sufficient sensitivity, with the exception of HRM for the discrimination of homozygotes. Given that tissue samples are often composed of various cells, including tumor infiltrating leukocytes, and the tumor itself can be highly heterogeneous (Gerlinger et al., 2012), it might be more informative to detect even the smallest amounts of mutated DNA, as it was demonstrated here and in other studies. While this approach may re- 
sult in detection of "passenger" mutations, even a low number of cancer cells harbouring $B R A F$ mutant alleles can be selected during progression of the disease (Lin et al., 2011).

In summary our results show that simple ARMS is a highly sensitive and cost effective method for $B R A F$ mutational screening (Table 1). Comparing real-time PCR based methods hybridizing probe-based detection seems to be more effective than the HRM assay. Limitations of our study include the number of samples tested and detection of only the most common $B R A F$ mutation.

\section{Acknowledgements}

This research was supported by the Polish Ministry of Science and Higher Education Grant No. N N401 034536 (to T.S.) and Medical University of Warsaw grant No. 1M19/PM18 (to E.G-M.). E. G-M. is a recipient of a fellowship for PhD Students co-financed by the European Union from the European Social Fund. M. M. Machnicki is supported by Postgraduate School of Molecular Medicine. We wish to thank Anna Czerepinska and Elzbieta Gutowska for excellent technical assistance.

\section{REFERENCES}

Arcaini L, Zibellini S, Boveri E, Riboni R, Rattotti S, Varettoni M, Guerrera ML, Lucioni M, Tenore A, Merli M, Rizzi S, Morello L, Cavalloni C, Da Via MC, Paulli M, Cazzola M (2012) The BRAF V600E mutation in hairy cell leukemia and other mature B-cell neoplasms. Blood 119: 188-191.

Badalian-Very G, Vergilio JA, Degar BA, MacConaill LE, Brandner B, Calicchio ML, Kuo FC, Ligon AH, Stevenson KE, Kehoe SM, Garraway LA, Hahn WC, Meyerson M, Fleming MD, Rollins BJ (2010) Recurrent BRAF mutations in Langerhans cell histiocytosis. Blood 116: 1919-1923.

Chapman MA, Lawrence MS, Keats JJ, Cibulskis K, Sougnez C, Schinzel AC, Harview CL, Brunet JP, Ahmann GJ, Adli M, Anderson KC, Ardlie KG, Auclair D, Baker A, Bergsagel PL, Bernstein BE, Drier Y, Fonseca R, Gabriel SB, Hofmeister CC, Jagannath S, Jakubowiak AJ, Krishnan A, Levy J, Liefeld T, Lonial S, Mahan S, Mfuko B, Monti S, Perkins LM, Onofrio R, Pugh TJ, Rajkumar SV, Ramos AH, Siegel DS, Sivachenko A, Stewart AK, Trudel S, Vij R, Voet D, Winckler W, Zimmerman T, Carpten J, Trent J, Hahn WC, Garraway LA, Meyerson M, Lander ES, Getz G, Golub TR (2011) Initial genome sequencing and analysis of multiple myeloma. Nature 471: 467-472

Chapman PB, Hauschild A, Robert C, Haanen JB, Ascierto P, Larkin J, Dummer R, Garbe C, Testori A, Maio M, Hogg D, Lorigan P, Lebbe C, Jouary T, Schadendorf D, Ribas A, O'Day SJ, Sosman JA, Kirkwood JM, Eggermont AM, Dreno B, Nolop K, Li J, Nelson B, Hou J, Lee RJ, Flaherty KT, McArthur GA (2011) Improved survival with vemurafenib in melanoma with BRAF V600E mutation. N Engl J Med 364: 2507-2516.

Chen Q, Lu P, Jones AV, Cross NC, Silver RT, Wang YL (2007) Amplification refractory mutation system, a highly sensitive and simple polymerase chain reaction assay, for the detection of JAK2 V617F mutation in chronic myeloproliferative disorders. J Mol Diagn 9: $272-276$.

Clamp M, Cuff J, Searle SM, Barton GJ (2004) The Jalview Java alignment editor. Bioinformatics 20: 426-427.

Cohen Y, Xing M, Mambo E, Guo Z, Wu G, Trink B, Beller U, Westra WH, Ladenson PW, Sidransky D (2003) BRAF mutation in papillary thyroid carcinoma. I Natl Cancer Inst 95: 625-627.

Davies H, Bignell GR, Cox C, Stephens P, Edkins S, Clegg S, Teague J, Woffendin H, Garnett MJ, Bottomley W, Davis N, Dicks E, Ewing $R$, Floyd $Y$, Gray $K$, Hall S, Hawes R, Hughes J, Kosmidou V, Menzies A, Mould C, Parker A, Stevens C, Watt S, Hooper S, Wilson R, Jayatilake H, Gusterson BA, Cooper C, Shipley J, Hargrave D, Pritchard-Jones K, Maitland N, Chenevix-Trench G, Riggins GJ, Bigner DD, Palmieri G, Cossu A, Flanagan A, Nicholson A, Ho JW, Leung SY, Yuen ST, Weber BL, Seigler HF, Darrow TL, Paterson H, Marais R, Marshall CJ, Wooster R, Stratton MR, Futreal PA (2002) Mutations of the BRAF gene in human cancer. Nature 417: 949-954.

Davison JM, Rosenbaum E, Barrett TL, Goldenberg D, Hoque MO, Sidransky D, Westra WH (2005) Absence of V599E BRAF mutations in desmoplastic melanomas. Cancer 103: 788-792.
Di Nicolantonio F, Martini M, Molinari F, Sartore-Bianchi A, Arena S, Saletti P, De Dosso S, Mazzucchelli L, Frattini M, Siena S, Bardelli A (2008) Wild-type BRAF is required for response to panitumumab or cetuximab in metastatic colorectal cancer. J Clin Oncol 26: 57055712.

Ellison G, Donald E, McWalter G, Knight L, Fletcher L, Sherwood J, Cantarini M, Orr M, Speake G (2010) A comparison of ARMS and DNA sequencing for mutation analysis in clinical biopsy samples. $J$ Exp Clin Cancer Res 29: 132.

Forbes SA, Bindal N, Bamford S, Cole C, Kok CY, Beare D, Jia M, Shepherd R, Leung K, Menzies A, Teague JW, Campbell PJ, Stratton MR, Futreal PA (2011) COSMIC: mining complete cancer genomes in the Catalogue of Somatic Mutations in Cancer. Nucleic Acids Res 39(Database issue): D945-950.

Garnett MJ, Marais R (2004) Guilty as charged: B-RAF is a human oncogene. Cancer Cell 6: 313-319.

Gerlinger M, Rowan AJ, Horswell S, Larkin J, Endesfelder D, Gronroos E, Martinez P, Matthews N, Stewart A, Tarpey P, Varela I, Phillimore B, Begum S, McDonald NQ, Butler A, Jones D, Raine K, Latimer C, Santos CR, Nohadani M, Eklund AC, Spencer-Dene B, Clark G, Pickering L, Stamp G, Gore M, Szallasi Z, Downward J, Futreal PA, Swanton C (2012) Intratumor heterogeneity and branched evolution revealed by multiregion sequencing. $N$ Engl J Med 366: 883-892.

Herrmann MG, Durtschi JD, Wittwer CT, Voelkerding KV (2007) Expanded instrument comparison of amplicon DNA melting analysis for mutation scanning and genotyping. Clin Chem 53(8): 1544-1548.

Hingorani SR, Jacobetz MA, Robertson GP, Herlyn M, Tuveson DA (2003) Suppression of BRAF(V599E) in human melanoma abrogates transformation. Cancer Res 63: 5198-5202.

Houben R, Becker JC, Kappel A, Terheyden P, Brocker EB, Goetz R, Rapp UR (2004) Constitutive activation of the Ras-Raf signaling pathway in metastatic melanoma is associated with poor prognosis. J Carinog 3: 6.

Janssen CS, Sibbett R, Henriquez FL, McKay IC, Kemp EG, Roberts $\mathrm{F}$ (2008) The T1799A point mutation is present in posterior uveal melanoma. Br J Cancer 99: 1673-1677.

Katoh K, Misawa K, Kuma K, Miyata T (2002) MAFFT: a novel method for rapid multiple sequence alignment based on fast Fourier transform. Nucleic Acids Res 30(14): 3059-3066.

Katoh K, Toh H (2008) Recent developments in the MAFFT multiple sequence alignment program. Brief Bioinform 9: 286-298.

Kopetz S DJ, Chan E, Hecht JR, O'Dwyer PJ, Lee RJ, Nolop KB, Saltz L (2010) PLX4032 in metastatic colorectal cancer patients with mutant BRAF tumors. J Clin Oncol 28:15s abstr 3534

Kotoula V, Sozopoulos E, Litsiou H, Fanourakis G, Koletsa T, Voutsinas G, Tseleni-Balafouta S, Mitsiades CS, Wellmann A, Mitsiades N (2009) Mutational analysis of the BRAF, RAS and EGFR genes in human adrenocortical carcinomas. Endocr Relat Cancer 16: 565-572.

Kumar R, Angelini S, Czene K, Sauroja I, Hahka-Kemppinen M, Pyrhonen S, Hemminki K (2003) BRAF mutations in metastatic melanoma: a possible association with clinical outcome. Clin Cancer Res 9: 3362-3368.

Libra M, Malaponte G, Navolanic PM, Gangemi P, Bevelacqua V, Proietti L, Bruni B, Stivala F, Mazzarino MC, Travali S, McCubrey JA (2005) Analysis of BRAF mutation in primary and metastatic melanoma. Cell Cycle 4: 1382-1384.

Lin J, Goto Y, Murata H, Sakaizawa K, Uchiyama A, Saida T, Takata M (2011) Polyclonality of BRAF mutations in primary melanoma and the selection of mutant alleles during progression. $\mathrm{Br}$ I Cancer 104: 464-468.

Maat W, Kilic E, Luyten GP, de Klein A, Jager MJ, Gruis NA, Van der Velden PA (2008) Pyrophosphorolysis detects B-RAF mutations in primary uveal melanoma. Invest Ophthalmol Vis Sci 49: 23-27.

Michaloglou C, Vredeveld LC, Soengas MS, Denoyelle C, Kuilman T, van der Horst CM, Majoor DM, Shay JW, Mooi WJ, Peeper DS (2005) BRAFE600-associated senescence-like cell cycle arrest of human naevi. Nature 436: 720-724.

Naoki K, Chen TH, Richards WG, Sugarbaker DJ, Meyerson M (2002) Missense mutations of the BRAF gene in human lung adenocarcinoma. Cancer Res 62: 7001-7003.

Newton CR, Graham A, Heptinstall LE, Powell SJ, Summers C, Kalsheker N, Smith JC, Markham AF (1989) Analysis of any point mutation in DNA. The amplification refractory mutation system (ARMS). Nucleic Acids Res 17: 2503-2516.

Pollock PM, Harper UL, Hansen KS, Yudt LM, Stark M, Robbins CM, Moses TY, Hostetter G, Wagner U, Kakareka J, Salem G, Pohida T, Heenan P, Duray P, Kallioniemi O, Hayward NK, Trent JM, Meltzer PS (2003) High frequency of BRAF mutations in nevi. Nat Genet 33: 19-20.

Robinson MJ, Cobb MH (1997) Mitogen-activated protein kinase pathways. Curr Opin Cell Biol 9: 180-186.

Rodriguez-Viciana P, Tetsu O, Tidyman WE, Estep AL, Conger BA, Cruz MS, McCormick F, Rauen KA (2006) Germline mutations in genes within the MAPK pathway cause cardio-facio-cutaneous syndrome. Science 311: 1287-1290. 
Rossi D, Rasi S, Fabbri G, Spina V, Fangazio M, Forconi F, Marasca R, Laurenti L, Bruscaggin A, Cerri M, Monti S, Cresta S, Fama R, De Paoli L, Bulian P, Gattei V, Guarini A, Deaglio S, Capello D, Rabadan R, Pasqualucci L, Dalla-Favera R, Foa R, Gaidano G (2012) Mutations of NOTCH1 are an independent predictor of survival in chronic lymphocytic leukemia. Blood 119: 521-529.

Rozen S, Skaletsky H (2000) Primer3 on the WWW for general users and for biologist programmers. Methods Mol Biol 132: 365-386.

Rubinstein JC, Sznol M, Pavlick AC, Ariyan S, Cheng E, Bacchiocchi A, Kluger HM, Narayan D, Halaban R (2010) Incidence of the V600K mutation among melanoma patients with BRAF mutations, and potential therapeutic response to the specific BRAF inhibitor PLX4032. J Transl Med 8: 67

Saridaki Z, Tzardi M, Papadaki C, Sfakianaki M, Pega F, Kalikaki A, Tsakalaki E, Trypaki M, Messaritakis I, Stathopoulos E, Mavroudis D, Georgoulias V, Souglakos J (2011) Impact of KRAS, BRAF, PIK3CA mutations, PTEN, AREG, EREG expression and skin rash in $>/=2$ line cetuximab-based therapy of colorectal cancer patients. PLoS One 6: e15980.

Schindler G, Capper D, Meyer J, Janzarik W, Omran H, Herold-Mende C, Schmieder K, Wesseling P, Mawrin C, Hasselblatt M, Louis DN, Korshunov A, Pfister S, Hartmann C, Paulus W, Reifenberger G, von Deimling A (2011) Analysis of BRAF V600E mutation in 1,320 nervous system tumors reveals high mutation frequencies in pleomorphic xanthoastrocytoma, ganglioglioma and extra-cerebellar pilocytic astrocytoma. Acta Neuropathol 121: 397-405.

Schmid K, Oehl N, Wrba F, Pirker R, Pirker C, Filipits M (2009) EGFR/KRAS/BRAF mutations in primary lung adenocarcinomas and corresponding locoregional lymph node metastases. Clin Cancer Res 15: 4554-4560.

Solit DB, Garraway LA, Pratilas CA, Sawai A, Getz G, Basso A, Ye Q, Lobo JM, She Y, Osman I, Golub TR, Sebolt-Leopold J, Sellers WR, Rosen N (2006) BRAF mutation predicts sensitivity to MEK inhibition. Nature 439: 358-362.
Tiacci E, Trifonov V, Schiavoni G, Holmes A, Kern W, Martelli MP, Pucciarini A, Bigerna B, Pacini R, Wells VA, Sportoletti P, Pettirossi V, Mannucci R, Elliott O, Liso A, Ambrosetti A, Pulsoni A, Forconi F, Trentin L, Semenzato G, Inghirami G, Capponi M, Di Raimondo F, Patti C, Arcaini L, Musto P, Pileri S, Haferlach C, Schnittger S, Pizzolo G, Foa R, Farinelli L, Haferlach T, Pasqualucci L, Rabadan R, Falini B (2011) BRAF mutations in hairy-cell leukemia. N Engl J Med 364: 2305-2315.

Trovisco V, Vieira de Castro I, Soares P, Maximo V, Silva P, Magalhaes J, Ảbrosimov A, Guiu XM, Sobrinho-Simoes M (2004) BRAF mutations are associated with some histological types of papillary thyroid carcinoma. J Pathol 202: 247-251.

Wan PT, Garnett MJ, Roe SM, Lee S, Niculescu-Duvaz D, Good VM, Jones CM, Marshall CJ, Springer CJ, Barford D, Marais R (2004) Mechanism of activation of the RAF-ERK signaling pathway by oncogenic mutations of B-RAF. Cell 116: 855-867.

Wang L, Cunningham JM, Winters JL, Guenther JC, French AJ, Boardman LA, Burgart LJ, McDonnell SK, Schaid DJ, Thibodeau SN (2003) BRAF mutations in colon cancer are not likely attributable to defective DNA mismatch repair. Cancer Res 63: 5209-5212.

Waterhouse AM, Procter JB, Martin DM, Clamp M, Barton GJ (2009) Jalview Version 2--a multiple sequence alignment editor and analysis workbench. Bioinformatics 25: 1189-1191.

Wittwer CT, Reed GH, Gundry CN, Vandersteen JG, Pryor RJ (2003) High-resolution genotyping by amplicon melting analysis using LCGreen. Clin Chem 49(6 Pt 1): 853-860.

Yancovitz M, Yoon J, Mikhail M, Gai W, Shapiro RL, Berman RS, Pavlick AC, Chapman PB, Osman I, Polsky D (2007) Detection of mutant BRAF alleles in the plasma of patients with metastatic melanoma. J Mol Diagn 9: 178-183.

Yokota T, Ura T, Shibata N, Takahari D, Shitara K, Nomura M, Kondo C, Mizota A, Utsunomiya S, Muro K, Yatabe Y (2011) BRAF mutation is a powerful prognostic factor in advanced and recurrent colorectal cancer. Br J Cancer 104: 856-862. 